\title{
Adverse prognosis of incidentally detected ambulatory atrial fibrillation
}

\section{A cohort study}

\author{
Carlos Martinez; Anja Katholing1; Saul Benedict Freedman² \\ ${ }^{1}$ Institute for Epidemiology, Statistics and Informatics GmbH, Frankfurt, Germany; ${ }^{2}$ Department of Cardiology Concord Hospital and Anzac Research Institute, Sydney Medical \\ School, University of Sydney, Australia
}

\begin{abstract}
Summary
It was the aim of this study to determine prognosis of incidentally detected ambulatory atrial fibrillation (IA-AF) and its response to antithrombotic therapy. We performed a cohort study of 5,555 patients with IA-AF (mean age $70.9 \pm 10.1,38.4 \%$ female) and 24,705 ageand gender-matched controls without AF followed three years using UK Clinical Practice Research Datalink. We measured incidence rates of stroke, all-cause mortality, myocardial infarction, major bleeding, and effect of antithrombotic therapy. Patients with IA-AF had mean $\mathrm{CHA}_{2} \mathrm{DS}_{2}$ VASc score $2.5 \pm 1.5,73 \%$ with score $\geq 2$. The stroke incidence rate (IR) was 19.4 (95\% confidence interval $17.1-21.9) / 1,000$ person-years vs $8.4(7.7-9.1)$ in controls $(p<0.001)$, mortality 40.1 $(36.8-43.6) / 1,000$ person-years vs $20.9(19.8-22.0)$ in controls $(\mathrm{p}<0.001)$, and myocardial infarction $9.0(7.5-10.8) / 1,000$ person-
\end{abstract}

Correspondence to:

Prof. S. Ben Freedman

Department of Cardiology, Concord Hospital 3W

Hospital Rd, Concord, NSW 2139, Australia

Tel.: + 6229767 7358, Fax: +6129767 6780

E-mail: ben.freedman@sydney.edu.au years vs $6.5(5.9-7.2)$ in controls $(p<0.001)$. IRs of all endpoints increased with age. Oral anticoagulant \pm antiplatelet therapy received by $51.0 \%$ in year following IA-AF was associated with adjusted hazard ratio (HR) of $0.35(0.17-0.71)$ for stroke, and $0.56(0.36-0.85)$ for death compared to no therapy, while antiplatelet treatment was associated with a non-significant reduction of HR: $0.81(0.51-1.29)$ for stroke, and $0.80(0.55-1.15)$ for death, though both carried a similar small non-significant adjusted excess IR of major bleeding. In conclusion, asymptomatic AF detected incidentally is associated with a significant adverse effect on stroke and death, with reduction in both associated with oral anticoagulant but not antiplatelet treatment. This provides justification to assess cost-effectiveness of community screening to detect unknown AF.

Received: April 24, 2014

Accepted after minor revision: May 14, 2014

Epub ahead of print: June 18, 2014

http://dx.doi.org/10.1160/TH4-04-0383

Thromb Haemost 2014; 112: 276-286

\section{Introduction}

Atrial fibrillation (AF) is increasing in prevalence (1) due in part to population ageing, and is associated with a significant but variable increase in risk of stroke (2) (usually large and severe) $(3,4)$, death (5) and heart failure(6). AF accounts for approximately $20-30 \%$ of all strokes (7) (8) though the incidence is rising (8) and this figure is an underestimate as many strokes are due to unknown $\mathrm{AF}$ (9-11). In $20-45 \%$ of AF-related stroke, the arrhythmia was not documented and often asymptomatic prior to stroke $(7,12)$. Incidentally discovered AF is usually not associated with palpitations, and resting heart rate is not elevated (13), which may explain why stroke is an unfortunate first manifestation of AF. Because AF-related strokes are largely preventable by oral anticoagulants (OAC) $(14,15)$, screening for asymptomatic AF is an attractive approach to reduce stroke burden.

While the stroke risk of AF has been well described, there is no information on incidentally diagnosed ambulatory AF (IA-AF). Data on the prognosis of IA-AF in the general population are required to inform recommendations about screening. Sub-clinical rapid atrial tachyarrhythmia documented by implanted pace- makers is associated with a significant increase in stroke $(11,16)$, but patients with implanted devices are not representative of the population with IA-AF $(13,17)$. The 2012 ESC AF guideline update now recommends opportunistic screening for asymptomatic AF in patients $\geq 65$ years (2), as does the Royal College of Physicians of Edinburgh (18), while AHA/ACC/ESC guidelines (19, 20) were silent on screening. The comprehensive 2014 AHA/ACC/ HRS update, states only that "Clinically unrecognized and asymptomatic $\mathrm{AF}$ is a potentially important cause of stroke, supporting efforts at early detection of AF in at-risk individuals", but makes no recommendation about screening (21). In our recent systematic review, we reported that a single electrocardiogram (ECG) or pulse check to screen for incidental ambulatory AF in subjects aged 65 or older would be likely to detect $1.4 \%$ with AF in both the general population and the clinic (22). Development of policy and recommendations on screening in guidelines including how widely to screen, and the most appropriate age cut-off, requires precise knowledge of the rate of incidental AF in different age groups, a consideration of the cost of the screening method, and critically, knowledge of the prognosis of individuals who might be detected. 
The objective of this study was to identify a large cohort with $\mathrm{IA}-\mathrm{AF}$, and estimate the excess risk of stroke, death, myocardial infarction and major bleeding compared with age and gendermatched ambulant patients without AF, and examine the effect of prescribed antithrombotic therapy on outcomes.

\section{Methods}

\section{Data source}

Data were obtained from the subset of the Clinical Practice Research Datalink (CPRD). This database is linked to Hospital Episodes Statistics (HES) and Central Mortality data of the Office for National Statistics (ONS). CPRD includes full primary care medical symptoms and diagnoses and GP-issued prescriptions and referrals. HES data include date of admission/discharge, primary and other main reasons for treatment recorded with ICD-10, and surgical operations and procedures during hospital stay recorded with OPCS-4 codes. ONS data consists of date and cause of death as recorded as ICD-10 in death certificates.

\section{Study cohort and design}

The study cohort was identified from all 18- to 84-year-old CPRD patients from 'up-to-standard' general practitioner (GP) practices with a link to HES and ONS. Eligible patients had a first-time recording of AF during January 1, 2001 and March 31, 2009 (index day) and were registered with the GP practice for at least one year prior to first AF recording.

To generate a cohort of incidentally detected ambulatory AF we excluded patients with AF who had a history of valvular heart disease or heart failure, use of digoxin, quinidine, sotatol, amiodarone flecainide or propafenone, a recording of irregular beats, prior cardioversion, or use of OACs in the year prior to the index day, as were patients with a study outcome or transient ischaemic attack (TIA) $\leq 14$ days before, or $\leq 7$ days following, the index day ( $>$ Figure 1). All patients with hospital-recorded AF were excluded from analysis. By careful practice review of 'Read Medical Codes' and ICD codes, we further removed patients with symptoms potentially indicative of AF including palpitations, syncope, collapse, weakness, dizziness, chest pain and dyspnoea depending on specified temporal relationships with the first-time recording of AF (full list in Suppl. Table 1a and b, available online at www.thrombo sis-online.com). For each IA-AF patient we randomly selected up to five patients in the CPRD cohort by matching birth year, gender, and index day: all matches met the same IA-AF inclusion and exclusion criteria.

IA-AF and matched non-AF cohorts underwent follow-up for a maximum of three years for occurrence of stroke, myocardial infarction (MI), all-cause mortality and major bleeding. Strokes consisted of ischaemic or unspecified strokes excluding intracranial bleeding, recorded in primary care, at hospital discharge or from death certificates. Fatal and non-fatal MI was identified from hospital discharge diagnoses and death certificates. Major bleeding was defined according to ISTH (23) and consisted of a) bleeds at a critical site, i.e. intraocular bleeding in non-diabetics, intracranial, intra-spinal, pericardial, intra-articular, retroperitoneal or intramuscular bleeding events with compartment syndrome, b) bleeding events with blood transfusion within seven days and c) bleeding events as one of the first three causes of death. Major bleeding events were not restricted to the first hospital episode. Deaths from any cause were identified by dates of death obtained from CPRD data and death certificates.

\section{Observational period}

The at-risk period for all study outcomes started seven days following index day and continued until first occurrence of any of the following: a specified study outcome, the patient's 'transferred-out

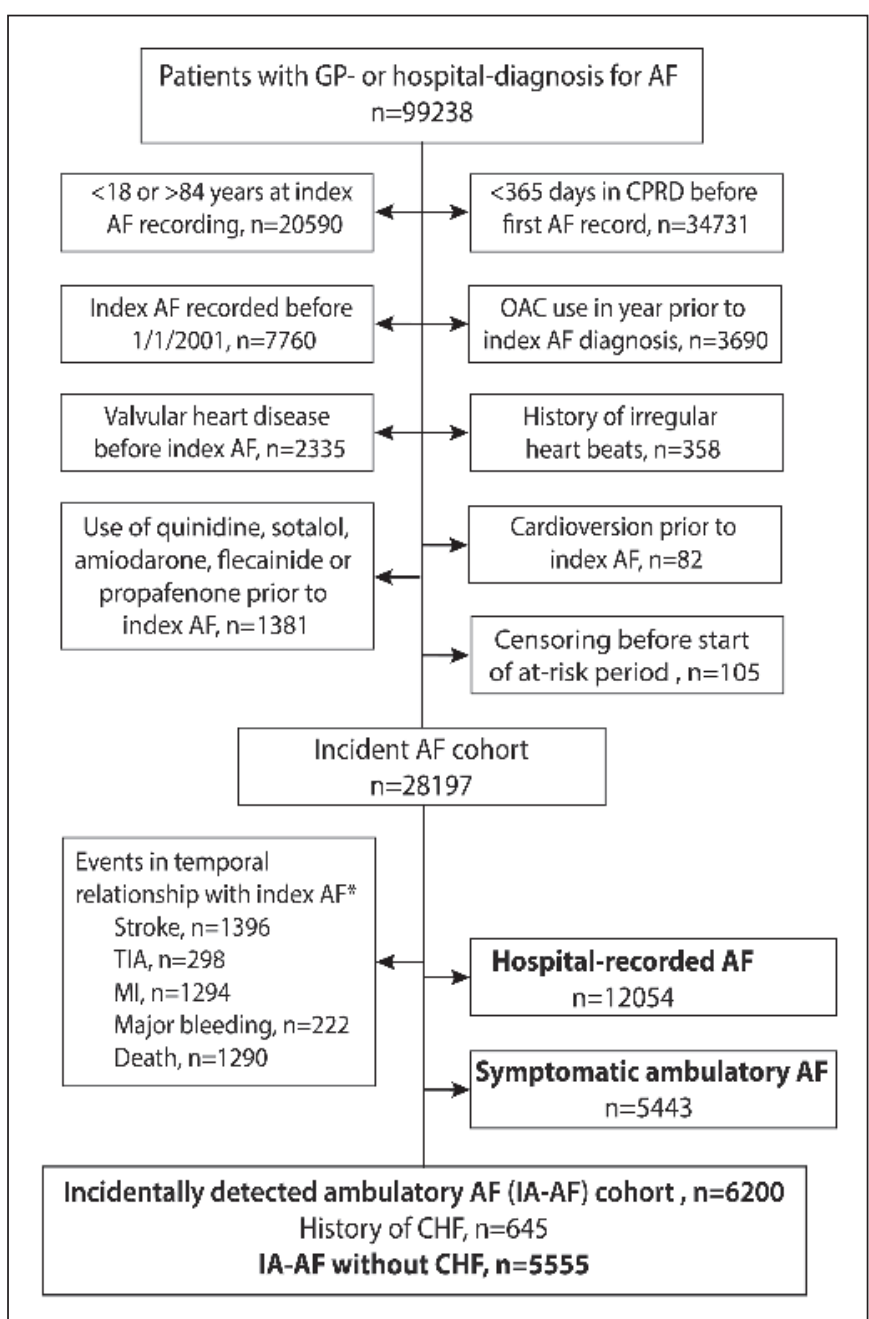

Figure 1: Generation of incidentally detected ambulatory AF cohort. AF: atrial fibrillation; CHF: congestive heart failure or use of cardiac glycosides; GP: general practitioner; MI: myocardial infarction; TIA: transient ischaemic attack; OAC: oral anticoagulant, defined by prescription of vitamin $\mathrm{K}$ antagonist (VKA), read medical codes or mentioning in clinical notes of VKA use, or $\geq 2$ INR tests in 60 days prior to index AF. *Study endpoint in the 14 days before the first $A F$ record, within hospital stay, or within 7 days following AF/hospital discharge. 
Table 1: Characteristics of IA-AF and matched non-AF cohort at index day, and subgroups of IA-AF cohort according to antithrombotic therapy use.

\begin{tabular}{|c|c|c|c|c|c|}
\hline & \multicolumn{4}{|c|}{ IA-AF cohort } & \multirow{2}{*}{$\begin{array}{l}\text { Matched non-AF } \\
\text { cohort }\end{array}$} \\
\hline & Total & $\mathrm{OAC} \pm \mathrm{APb}$ & AP only & Neither OACs nor AP & \\
\hline Total & 5555 & 2492 & 1603 & 1460 & 24705 \\
\hline Agea mean $\pm S D$ & $70.9 \pm 10.1$ & $70.7 \pm 9.0$ & $73.8 \pm 7.9$ & $68.1 \pm 12.9$ & $70.9 \pm 10.1$ \\
\hline Median age (IQR) & $73(65,79)$ & $72(66,77)$ & $75(69,80)$ & $72(60,79)$ & $73(65,79)$ \\
\hline Age $\geq 75$ & $2407(43.3)$ & $957(38.4)$ & $871(54.3)$ & $579(39.7)$ & $10028(43.3)$ \\
\hline Female gender ${ }^{\mathrm{a}}$ & $2133(38.4)$ & $863(34.6)$ & $685(42.7)$ & $585(40.1)$ & $9582(38.4)$ \\
\hline BMI & $27.8 \pm 5.3$ & $28.3 \pm 5.3$ & $27.7 \pm 5.4$ & $27.1 \pm 5.3$ & $26.5 \pm 4.5$ \\
\hline Current smoker & $652(11.7)$ & $261(10.5)$ & $180(11.2)$ & $211(14.5)$ & $3642(14.4)$ \\
\hline $\mathrm{CHADS}_{2}{ }^{\mathrm{a}}$ score, mean $\pm \mathrm{SD}$ & $1.3 \pm 1.1$ & $1.3 \pm 1.1$ & $1.5 \pm 1.1$ & $1.0 \pm 1.0$ & $1.1 \pm 1.1$ \\
\hline $\mathrm{CHA}_{2} \mathrm{DS}_{2}$ VASC $\mathrm{C}^{\mathrm{a}}$ score, mean $\pm \mathrm{SD}$ & $2.5 \pm 1.5$ & $2.5 \pm 1.5$ & $2.9 \pm 1.4$ & $2.1 \pm 1.5$ & $2.3 \pm 1.5$ \\
\hline Diabetes & $632(11.4)$ & $301(12.1)$ & $224(14.0)$ & $107(7.3)$ & $2450(10.2)$ \\
\hline Hypertension & $2984(53.7)$ & $1391(55.8)$ & $969(60.4)$ & $624(42.7)$ & 9565 (39.4) \\
\hline CHF & $0(0.0)$ & $0(0.0)$ & $0(0.0)$ & $0(0.0)$ & $0(0.0)$ \\
\hline $\mathrm{Ml}$ & $232(4.2)$ & $108(4.3)$ & $79(4.9)$ & $45(3.1)$ & $1194(5.0)$ \\
\hline Coronary artery disease without MI & $590(10.6)$ & $272(10.9)$ & $235(14.7)$ & $83(5.7)$ & 2771 (11.5) \\
\hline Stroke/TIA & $509(9.2)$ & $242(9.7)$ & $181(11.3)$ & $86(5.9)$ & $1474(6.2)$ \\
\hline Charlson score, mean \pm SD & $0.94 \pm 1.33$ & $0.88 \pm 1.23$ & $1.10 \pm 1.45$ & $0.88 \pm 1.35$ & $0.87 \pm 1.35$ \\
\hline
\end{tabular}

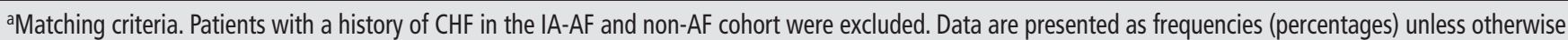
stated. OAC: oral anticoagulants, AP: antiplatelets. IA-AF: incidentally detected ambulatory atrial fibrillation cohort; BMI: body mass index; CHF: congestive heart failure; IQR: interquartile range; MI: history of myocardial infarction; SD: standard deviation. Percentages for matched non-AF cohort weighted by the number of non-AF subjects matched to each IA-AF patient. ${ }^{b} \mathrm{OAC}$ and $\mathrm{AP}$ use defined by any use within 180 days. $\mathrm{OAC} \pm \mathrm{AP}$ : includes 817 patients with use of $\mathrm{OAC}$ and $\mathrm{AP}$ in the 180 days following IA-AF.

day' of the practice, the last collection date of the practice, October 31,2010 , or the completion of three years of observation following $\mathrm{AF}$ diagnosis. Patients in the non-AF reference cohort were censored with a diagnosis of AF.

\section{Use of antithrombotics}

OAC use consisted of prescriptions for oral vitamin $\mathrm{K}$ antagonists, 'Read medical codes' and medical note review indicating use of OACs \pm concomitant antiplatelets. We performed an electronic search for "warfarin" and "International normalised ratio (INR)" in the medical notes of the subset of the IA-AF cohort not exposed to OACs. All anonymised medical notes with an entry for warfarin and/or INR were manually reviewed to assess whether patients were given OACs. Use of antiplatelet medications was defined by prescriptions of aspirin and/or clopidogrel. Exposure to antiplatelets and OACs ended 60 days after a prescription or when medical codes/notes indicated that they were either stopped or not tolerated. Non-vitamin K anticoagulant (VKA) oral anticoagulants were not available during the study period.

\section{Data analysis}

Descriptive characteristics of the non-AF matched control group were weighted by the inverse of their number in each matched set. Crude incidence rates were calculated by number of incident outcome events during the study period divided by total person-years at risk. Cumulative risk of all-cause mortality was provided using Kaplan-Meier cumulative incidence estimates. Proportional hazards regression analysis was used to assess the prognostic significance of IA-AF in association with all-cause mortality when compared to non-AF after adjusting for age, gender, smoking, hypertension, diabetes, previous TIA/stroke, coronary artery disease, peripheral artery disease, previous bleeding, cancer, AP therapy in previous year and Charlson index $(0,1,2,3,4,5+)$.

For stroke and MI, competing risk analysis was performed to present crude cumulative risk over time accounting for mortality as a competing risk (24). The prognostic significance of IA-AF vs non- $\mathrm{AF}$ was assessed with cumulative risk regression analysis accounting for death as a competing risk (25). For all outcomes, adjusted cumulative risk curves were derived by standardising the non-AF cohort to the baseline prevalence of IA-AF cohort characteristics. The prognostic effect of $\mathrm{OAC} \pm$ antiplatelets and antipla- 
telet use only, was assessed using OAC and antiplatelet treatment as a time-dependent covariate compared to no treatment.

Log-log survival plots and Schoenfeld residuals for IA-AF versus non-AF and for OAC vs no OAC were used to test the proportional hazards and sub-hazards assumptions, respectively. As the assumption for OAC was fulfilled only for 1.5 years following IA$\mathrm{AF}$, we limited the analysis to 1.5 years. The hazard function of stroke among patients with IA-AF describes the rate of stroke at each instance of time in the three years after index IA-AF. The hazard function was estimated as a smoothed curve using cubic splines in a generalised additive model $(26,27)$. All statistical procedures were performed using STATA MP Version 12.1 (StataCorp LP).

\section{Approval and funding}

The study protocol was approved by the Independent Scientific Advisory Committee for GPRD research. There was no external funding for the study.

\section{Results}

A total of 6,200 patients with IA-AF were identified, of whom 645 had a history of heart failure and were excluded as symptoms might potentially be confused with those of AF, leaving a cohort of 5,555 patients with asymptomatic IA-AF and 24,705 matched controls (see $>$ Figure 1). Characteristics of both cohorts are shown in Table 1. Mean $\mathrm{CHADS}_{2}$ and $\mathrm{CHA}_{2} \mathrm{DS}_{2}$ VASc scores were slightly

Table 2: Crude incidence rate of stroke, MI, all-cause mortality and major bleeding in IA-AF and matched non-AF cohort by age.

\begin{tabular}{|c|c|c|c|c|c|c|c|}
\hline \multirow[t]{2}{*}{ Age } & \multicolumn{3}{|l|}{ IA-AF cohort } & \multicolumn{3}{|c|}{ Matched non-AF cohort } & \multirow{2}{*}{$\begin{array}{l}\text { Crude excess IR per } \\
1,000 \mathrm{PY} \\
(95 \% \mathrm{Cl})\end{array}$} \\
\hline & Stroke (n) & PY & $\begin{array}{l}\text { IR per 1,000 PY } \\
(95 \% \mathrm{CI})\end{array}$ & Stroke (n) & PY & $\begin{array}{l}\text { IR per 1,000 PY } \\
(95 \% \mathrm{CI})\end{array}$ & \\
\hline 18 to 49 & 0 & 564 & $0.0(0.0-6.5)$ & 0 & 2954 & $0.0(0.0-1.2)$ & $0.0(0.0 ; 0.0)$ \\
\hline 50 to 64 & 25 & 2761 & $9.1(5.9-13.4)$ & 31 & 13891 & $2.3(1.5-3.2)$ & $6.8(3.2 ; 10.5)$ \\
\hline 65 to 74 & 79 & 4774 & $16.5(13.1-20.6)$ & 131 & 22703 & $5.7(4.7-6.8)$ & $10.9(7.1 ; 14.6)$ \\
\hline 75 to 84 & 152 & 5128 & $29.6(25.1-34.7)$ & 356 & 25237 & $14.3(12.9-15.9)$ & $15.3(10.4 ; 20.3)$ \\
\hline \multirow[t]{2}{*}{ Total } & 256 & 13227 & $19.4(17.1-21.9)$ & 518 & 64785 & $8.4(7.7-9.1)$ & $11.0(8.5 ; 13.5)$ \\
\hline & MI (n) & PY & IR per $1,000 \mathrm{PY}$ & MI (n) & PY & IR per 1,000 PY & $\begin{array}{l}\text { Crude excess IR per } \\
\text { 1,000 PY }\end{array}$ \\
\hline 18 to 49 & 2 & 561 & $3.6(0.4-12.9)$ & 4 & 2948 & $1.3(0.4-3.5)$ & $2.2(-2.9 ; 7.3)$ \\
\hline 50 to 64 & 19 & 2768 & $6.9(4.1-10.7)$ & 35 & 13892 & $2.5(1.7-3.5)$ & $4.3(1.1 ; 7.5)$ \\
\hline 65 to 74 & 37 & 4835 & $7.7(5.4-10.5)$ & 107 & 22748 & $4.8(3.9-5.7)$ & $2.9(0.3 ; 5.5)$ \\
\hline 75 to 84 & 63 & 5246 & $12.0(9.2-15.4)$ & 254 & 25367 & $10.4(9.2-11.7)$ & $1.6(-1.6 ; 4.8)$ \\
\hline \multirow[t]{2}{*}{ Total } & 121 & 13411 & $9.0(7.5-10.8)$ & 400 & 64956 & $6.5(5.9-7.2)$ & $2.5(0.8 ; 4.2)$ \\
\hline & Mortality (n) & PY & IR per 1,000 PY & Mortality (n) & PY & IR per $1,000 \mathrm{PY}$ & $\begin{array}{l}\text { Crude excess IR per } \\
\text { 1,000 PY }\end{array}$ \\
\hline 18 to 49 & 4 & 564 & $7.1(1.9-18.2)$ & 2 & 2954 & $0.7(0.1-2.4)$ & $6.4(-0.6 ; 13.4)$ \\
\hline 50 to 64 & 47 & 2789 & $16.9(12.4-22.4)$ & 63 & 13930 & $4.5(3.4-5.7)$ & $12.4(7.5 ; 17.3)$ \\
\hline 65 to 74 & 149 & 4868 & $30.6(25.9-35.9)$ & 268 & 22847 & $11.9(10.5-13.4)$ & $18.7(13.6 ; 23.9)$ \\
\hline 75 to 84 & 342 & 5298 & $64.5(57.9-71.8)$ & 945 & 25547 & $38.0(35.7-40.5)$ & $26.6(19.3 ; 33.8)$ \\
\hline \multirow[t]{2}{*}{ Total } & 542 & 13520 & $40.1(36.8-43.6)$ & 1278 & 65278 & $20.9(19.8-22.0)$ & $19.2(15.7 ; 22.8)$ \\
\hline & $\begin{array}{l}\text { Major bleeding } \\
\text { (n) }\end{array}$ & PY & IR per 1,000 PY & $\begin{array}{l}\text { Major bleeding } \\
\text { (n) }\end{array}$ & PY & IR per 1,000 PY & $\begin{array}{l}\text { Crude excess IR per } \\
\text { 1,000 PY }\end{array}$ \\
\hline 18 to 49 & 1 & 564 & $1.8(0.0-9.9)$ & 2 & 2953 & $0.7(0.1-2.4)$ & $1.1(-2.5 ; 4.7)$ \\
\hline 50 to 64 & 10 & 2773 & $3.6(1.7-6.6)$ & 19 & 13912 & $1.3(0.8-2.1)$ & $2.2(-0.1 ; 4.6)$ \\
\hline 65 to 74 & 37 & 4828 & $7.7(5.4-10.6)$ & 66 & 22783 & $2.9(2.2-3.7)$ & $4.8(2.2 ; 7.4)$ \\
\hline 75 to 84 & 56 & 5256 & $10.7(8.0-13.8)$ & 157 & 25449 & $6.4(5.5-7.5)$ & $4.2(1.3 ; 7.2)$ \\
\hline Total & 104 & 13421 & 7.7 (6.3-9.4) & 244 & 65098 & $4.0(3.5-4.5)$ & $3.8(2.2 ; 5.4)$ \\
\hline
\end{tabular}



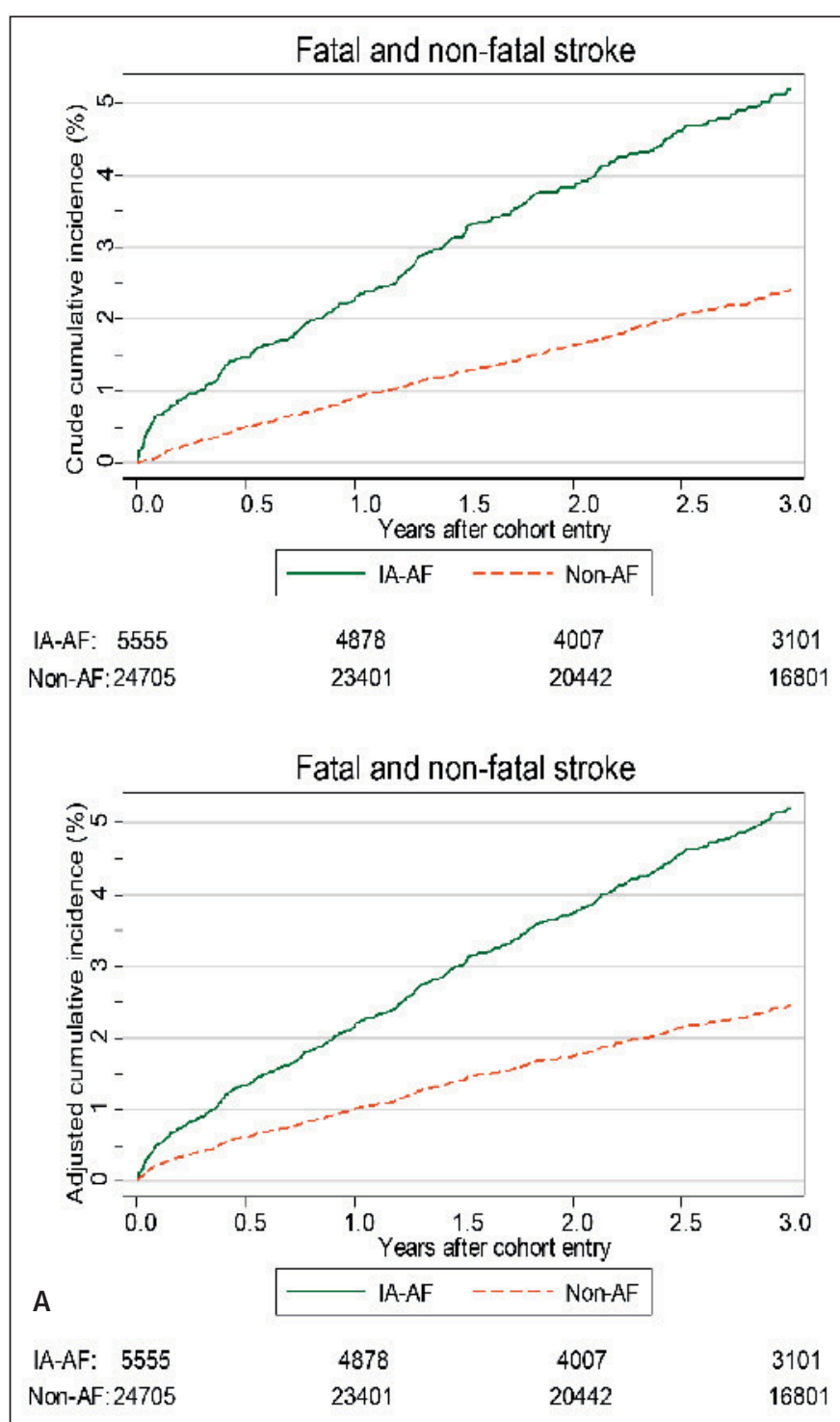

Figure 2: Crude and adjusted cumulative risk of stroke and all cause mortality in IA-AF and non-AF cohort (A), and crude and adjusted cumulative risk of major bleeding and $\mathrm{MI}$ in $\mathrm{IA}-\mathrm{AF}$ and non-AF cohort (B). IA-AF: incidentally detected ambulatory AF. Adjusted for age,

higher in the IA-AF group ( $\mathrm{p}<0.01$ for both). The proportion with $\mathrm{CHADS}_{2}$ score $\geq 2$ was significantly higher in IA-AF $(36.7 \%$ vs $28.9 \%, \mathrm{p}<0.01)$, as was the proportion with $\mathrm{CHA}_{2} \mathrm{DS}_{2} \mathrm{VASc}$ score $\geq 2(73 \%$ vs $68.0 \%, p<0.01)$. Similarly, the proportion with diabetes, hypertension and prior stroke/TIA was higher in IA-AF $(\mathrm{p}<0.01)$. The Charlson score, an index of co-morbidity, was greater in the IA-AF cohort $(\mathrm{p}<0.01)$.

Just over half $(2,832$ of 5,555$)$ the patients with IA-AF were treated with OACs in the year following diagnosis and $44.9 \%$ $(2,492$ of 5,555$)$ after 180 days, with little difference in this proportion according to $\mathrm{CHADS}_{2}$ or $\mathrm{CHA}_{2} \mathrm{DS}_{2} \mathrm{VASc}$ scores. In contrast, $0.2 \%$ (52 of 24,705) of controls received OACs during the same period. Almost half $(2,455$ of 5,555$)$ of the IA-AF group received antiplatelet drugs in the 180 days following AF diagnosis, largely
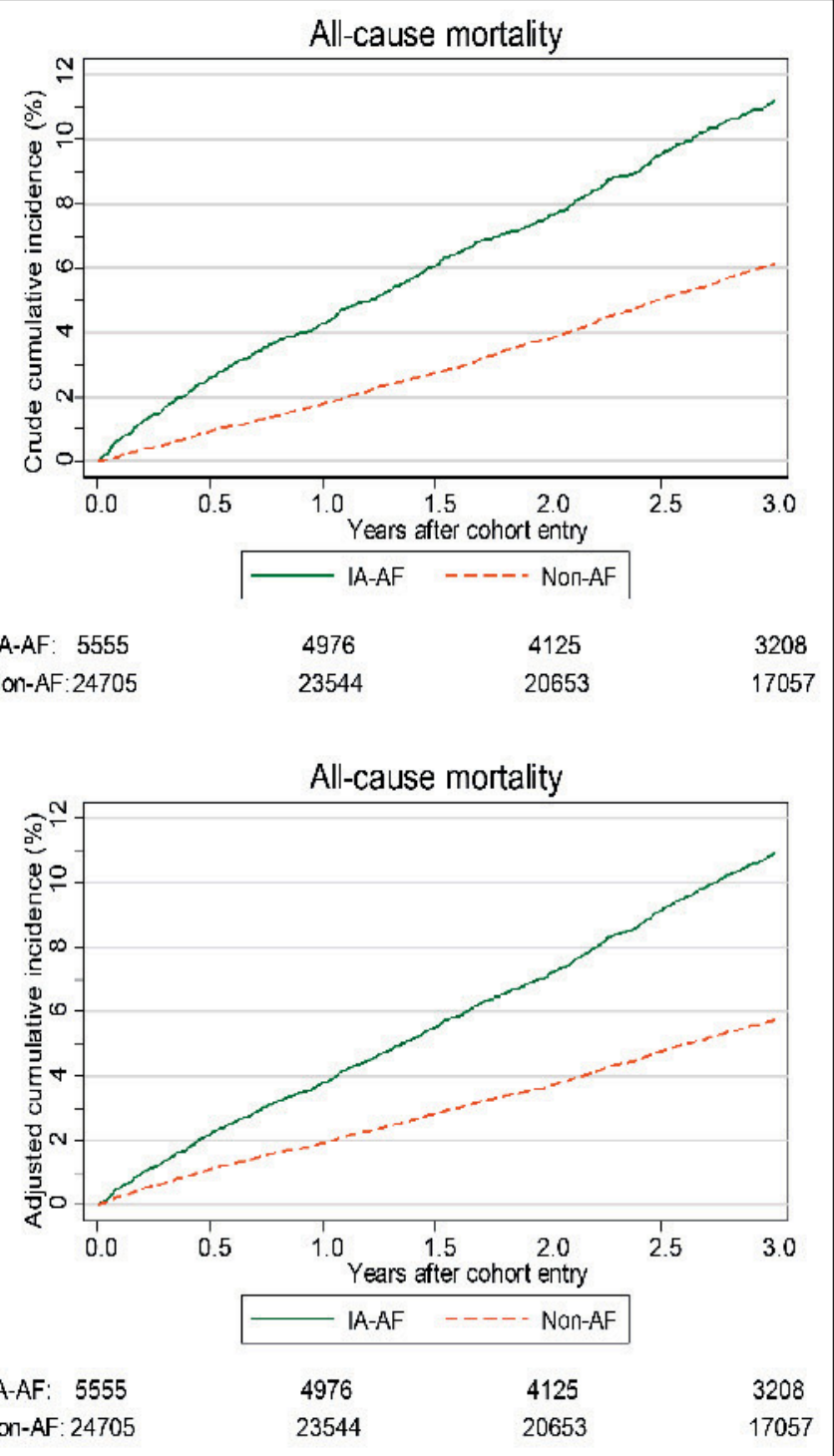

gender, smoking, hypertension, diabetes, previous TIA/stroke, coronary artery disease, peripheral artery disease, previous bleeding, cancer, AP therapy in previous year and Charlson index $(0,1,2,3,4,5+)$.

aspirin, compared to $20.0 \%$ (4,930 of 24,705) of controls. Persistence of OAC use was $71.7 \%$ at six months and $58.0 \%$ at one year (Suppl. Figure 1, available online at www.thrombosis-online.com).

Of the 5,555 patients with IA-AF, 542 died, 256 had a stroke, 121 an MI and 104 a major bleed during follow-up. Crude incidence rates and crude and adjusted cumulative incidence of the major outcomes are shown in $>$ Table 2 and $>$ Figure 2. Patients with IA-AF had a 2.3-fold increase in incidence rate of stroke compared to matched controls, with corresponding cumulative risk curves continuing to diverge across three years of follow-up. This equates to an annual excess stroke incidence rate of 11.0 (95\% confidence interval 8.5 to 13.5 )/1,000 person-years across the three years. This was associated with a doubling of the crude annual allcause mortality rate from 20.9 to $40.1 / 1,000$ person-years ( Table 


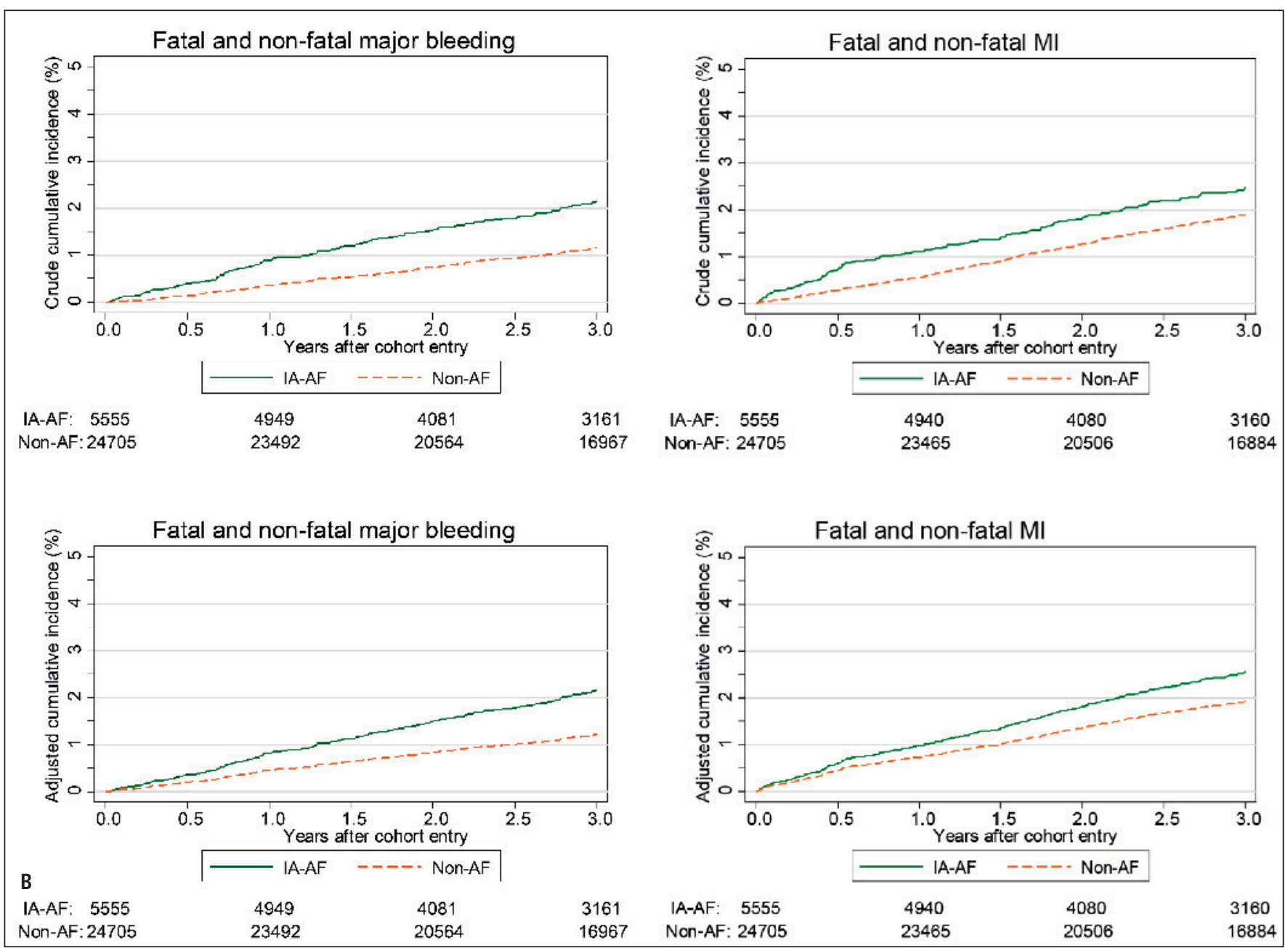

Figure 2: Continued

2) and an annual excess mortality rate of 19.2 (15.7 to 22.8$) / 1,000$ person-years, again with curves continuing to diverge across the three years of follow-up. The differences in the cumulative stroke, mortality, MI and bleeding risks did not change appreciably after adjustment for age, gender, smoking, hypertension, diabetes, previous TIA/stroke, coronary artery disease, peripheral artery disease, previous bleeding, cancer, antiplatelet therapy in previous year and Charlson index ( Figure 2A-B, lower panel).

Anticoagulation with OACs (exclusively VKAs) alone or with concomitant antiplatelet therapy in patients with IA-AF was associated with reduction of stroke ( Figure 3, $\$ Table 3 ), with an adjusted hazard ratio (HR) of 0.35 (0.17 to 0.71 ), while antiplatelet therapy was associated with a non-significant stroke reduction [adjusted HR 0.81 (0.51 to 1.29)]. The adjusted decrease in stroke incidence rate was 28.2 (17.3 to 39.1)/1,000 person-years. Reduction in mortality was also significantly associated with OAC use, [adjusted HR 0.56 (0.36 to 0.85)], while antiplatelet therapy was associated with a smaller non-significant reduction [adjusted HR $0.80(0.55$ to 1.15$)]$. The number needed to treat with OAC to prevent one stroke was 36 persons per year (26 to 58 ), and 36 persons per year (22 to 105) to prevent one death. Both OAC and antipla- telet therapy were associated with reduction of $\mathrm{MI}$ incidence [adjusted HR 0.32 (0.12 to 0.83 ) for OAC and 0.40 (0.16 to 0.99$)$ for antiplatelets]. Major bleeding, as might be expected from antithrombotic therapy, was higher in the IA-AF patients, with an annual incidence rate of 7.7 (6.3 to 9.4)/1,000 person-years, compared to 4.0 (3.5 to 4.5) in controls ( Table 2). The risk of major bleeding was increased similarly though not significantly by OAC and antiplatelet therapy, with adjusted HR of 1.48 (0.59 to 3.72) for $\mathrm{OAC}$ and 1.51 (0.63 to 3.61) for antiplatelet therapy. This equated to a non-significant adjusted excess in major bleeding incidence with OAC of 3.4 (-10.4 to 17.1)/1,000 person-years (-Table 3, - Figure 2B). Because combined OAC and antiplatelet therapy accounted for only $5.1 \%$ of the total person years of treatment with $\mathrm{OAC} \pm$ antiplatelet, it was not meaningful to analyse this subgroup separately for any of the above outcomes. In a sensitivity analysis when excluding patients with a history of the respective study outcome, the reduction of stroke and MI was consistent with our findings although the point estimate for the excess risk for MI was smaller ( $\triangleright$ Table 3, $\triangleright$ Figure 2B and Suppl. Table 2, available online at www.thrombosis-online.com). 


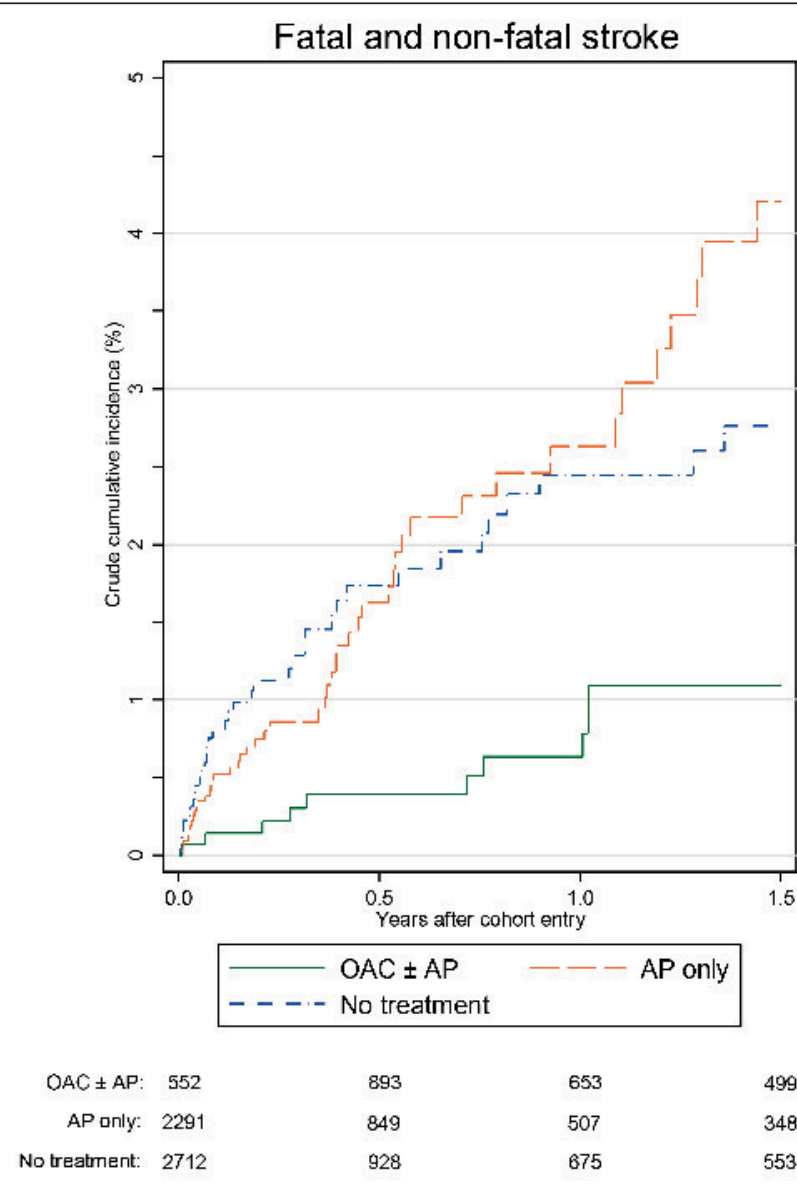

Figure 3: Crude and adjusted cumulative incidence of stroke by antithrombotic treatment. OAC: oral anticoagulant; AP: antiplatelets; First $O A C$ and $A P$ treatment episodes start in the first year after initial AF diagnosis. No treatment includes the person time prior to the first OAC/AP treatment episode or time until the end of observation (if patients remain un-

There was a significant relationship between age and excess incidence rate of most outcome endpoints in IA-AF compared to controls ( $>$ Table 2). Crude stroke incidence began to rise from age 50 with an excess risk over matched controls seen from 50 , but rising more steeply over age 65 to 10.9 (7.1 to 14.6$) / 1,000$ personyears for ages 65-74, and 15.3 (10.4 to 20.3)/1,000 person-years for $\geq 75$. A similar though quantitatively larger relationship was seen for all-cause mortality with a progressive rise with age to an excess crude mortality rate of 18.7 (13.6 to 23.9)/1,000 person-years between $65-74$, and 26.6 (19.3 to 33.8$) / 1,000$ person-years $\geq 75$. Major bleeding also showed an increase with age, but appeared to plateau over age 65 to a crude excess incidence rate of 4.2 to 4.8/1,000 person-years.

As might be anticipated, $\mathrm{CHA}_{2} \mathrm{DS}_{2} \mathrm{VASc}$ score showed a progressive relationship with risk of stroke (Suppl. Table 3, available online at www.thrombosis-online.com), and all elements of $\mathrm{CHA}_{2} \mathrm{DS}_{2}$ VASc score individually were related to stroke risk (not shown). Stroke risk was highest in the first year after IA-AF diagnosis only for those receiving no OAC treatment (Suppl. Figure 2, available online at www.thrombosis-online.com), while stroke risk

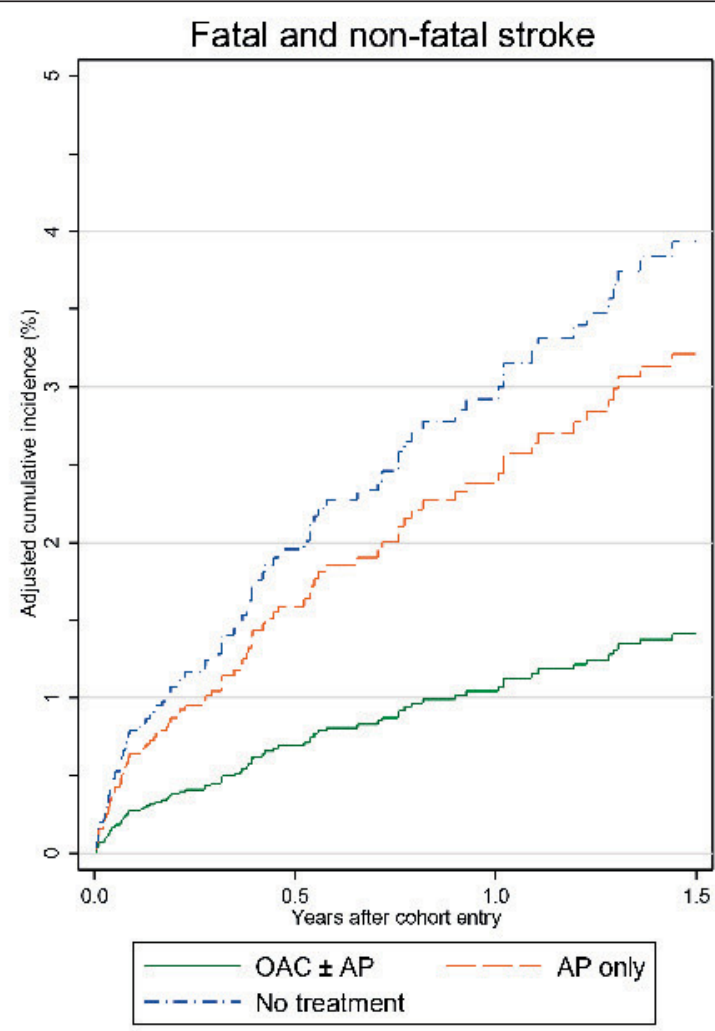

499

348

treated). Cumulative incidence adjusted for age, gender, smoking, hypertension, diabetes, previous TIA/stroke, coronary artery disease, peripheral artery disease, previous major bleeding, cancer, AP therapy in previous year and Charlson index $(0,1,2,3,4,5+)$.

was constant in the patients on OAC, and consistently lower than in the untreated group.

\section{Discussion}

Our principal finding is that the incidental diagnosis of $\mathrm{AF}$ in asymptomatic ambulatory patients well enough to be treated without referral to hospital, carried a substantial adverse prognosis with increased risk of stroke, death and MI compared to age- and gender-matched controls. For stroke this amounted to a 2.3 -fold increase vs controls, with an absolute increase of 11.0 strokes $/ 1,000$ person-years over three years, and significantly greater in the first six months after diagnosis. Most striking was the 19.2/1,000 person-year excess in all-cause mortality after diagnosis of IA-AF. These excess stroke and mortality rates underestimate outcome of undetected AF, as half of the IA-AF cohort were placed on OAC. This is the first time such a large dataset has been available: until now, it has only been possible to assume that the prognosis of incidentally detected ambulatory asymptomatic AF was similar to 
Table 3: Risk of study outcomes with corresponding excess incidence rates during the first treatment episode with OACs with or without antiplatelets, and antiplatelets only in IA-AF cohort and an observational period of up to 1.5 years.

\begin{tabular}{|c|c|c|c|c|c|c|c|c|}
\hline \multirow[t]{2}{*}{ Stroke } & \multirow{2}{*}{$\begin{array}{l}\text { All cases } \\
\text { (fatal } \\
\text { cases) }^{b}\end{array}$} & \multirow{2}{*}{$\begin{array}{l}\text { Person- } \\
\text { years }\end{array}$} & \multirow{2}{*}{$\begin{array}{l}\text { Crude IR } \\
\text { per } 1,000 \text { PY } \\
(95 \% \mathrm{CI})\end{array}$} & \multirow{2}{*}{$\begin{array}{l}\text { Crude HRc } \\
(95 \% \mathrm{CI})\end{array}$} & \multicolumn{2}{|c|}{ Principal analysis } & \multicolumn{2}{|c|}{ Sensitivity analysis } \\
\hline & & & & & $\begin{array}{l}\text { Adjusted HRc } \\
(95 \% \mathrm{Cl})\end{array}$ & $\begin{array}{l}\text { Adjusted excess } \\
\text { IR per 1,000 PY } \\
(95 \% \mathrm{CI})\end{array}$ & $\begin{array}{l}\text { Adjusted } \text { HR }^{d} \\
(95 \% \mathrm{Cl})\end{array}$ & $\begin{array}{l}\text { Adjusted excess } \\
\text { IR per 1,000 PYd } \\
(95 \% \mathrm{CI})\end{array}$ \\
\hline Untreated & $38(4)$ & 1399.4 & $\begin{array}{l}27.2 \\
(19.2-37.3)\end{array}$ & 1 & 1 & & 1 & \\
\hline $\begin{array}{l}\text { First OAC treatment } \\
\text { episode }^{\mathrm{a}}\end{array}$ & $10(1)$ & 1109.7 & $\begin{array}{l}9.0 \\
(4.3-16.6)\end{array}$ & $\begin{array}{l}0.41 \\
(0.20-0.82)\end{array}$ & $\begin{array}{l}0.35 \\
(0.17-0.71)\end{array}$ & $\begin{array}{l}-28.2 \\
(-39.1 ;-17.3)\end{array}$ & $\begin{array}{l}0.32 \\
(0.14-0.69)\end{array}$ & $\begin{array}{l}-26.1 \\
(-35.4 ;-16.7)\end{array}$ \\
\hline $\begin{array}{l}\text { First AP treatment } \\
\text { episode }^{\mathrm{a}}\end{array}$ & $47(3)$ & 1288.1 & $\begin{array}{l}36.5 \\
(26.8-48.5)\end{array}$ & $\begin{array}{l}1.27 \\
(0.82-1.97)\end{array}$ & $\begin{array}{l}0.81 \\
(0.51-1.29)\end{array}$ & $\begin{array}{l}-8.9 \\
(-29.9 ; 12.1)\end{array}$ & $\begin{array}{l}0.73 \\
(0.44-1.23)\end{array}$ & $\begin{array}{l}-10.1 \\
(-27.9 ; 7.7)\end{array}$ \\
\hline \multicolumn{9}{|l|}{ MI } \\
\hline Untreated & $20(2)$ & 1400.2 & $\begin{array}{l}14.3 \\
(8.7-22.1)\end{array}$ & 1 & 1 & & 1 & \\
\hline $\begin{array}{l}\text { First OAC treatment } \\
\text { episode }^{\mathrm{a}}\end{array}$ & $6(3)$ & 1120.6 & $\begin{array}{l}5.4 \\
(2.0-11.7)\end{array}$ & $\begin{array}{l}0.42 \\
(0.17-1.06)\end{array}$ & $\begin{array}{l}0.32 \\
(0.12-0.83)\end{array}$ & $\begin{array}{l}-16.9 \\
(-27.5 ;-6.3)\end{array}$ & $\begin{array}{l}0.38 \\
(0.13-1.09)\end{array}$ & $\begin{array}{l}-10.1 \\
(-19.3 ;-1.0)\end{array}$ \\
\hline $\begin{array}{l}\text { First AP treatment } \\
\text { episode }^{\mathrm{a}}\end{array}$ & $14(4)$ & 1296.3 & $\begin{array}{l}10.8 \\
(5.9-18.1)\end{array}$ & $\begin{array}{l}0.73 \\
(0.37-1.46)\end{array}$ & $\begin{array}{l}0.40 \\
(0.16-0.99)\end{array}$ & $\begin{array}{l}-14.5 \\
(-26.9 ;-2.1)\end{array}$ & $\begin{array}{l}0.52 \\
(0.20-1.39)\end{array}$ & $\begin{array}{l}-7.8 \\
(-18.8 ; 3.2)\end{array}$ \\
\hline \multicolumn{9}{|l|}{ Mortality } \\
\hline Untreated & 76 & 1404.1 & $\begin{array}{l}54.1 \\
(42.6-67.7)\end{array}$ & 1 & 1 & & & \\
\hline $\begin{array}{l}\text { First OAC treatment } \\
\text { episode }^{\mathrm{a}}\end{array}$ & 33 & 1124.7 & $\begin{array}{l}29.3 \\
(20.2-41.2)\end{array}$ & $\begin{array}{l}0.57 \\
(0.38-0.85)\end{array}$ & $\begin{array}{l}0.56 \\
(0.36-0.85)\end{array}$ & $\begin{array}{l}-28.0 \\
(-46.4 ;-9.5)\end{array}$ & & \\
\hline $\begin{array}{l}\text { First AP treatment } \\
\text { episode }^{\mathrm{a}}\end{array}$ & 68 & 1303 & $\begin{array}{l}52.2 \\
(40.5-66.2) \\
\end{array}$ & $\begin{array}{l}0.94 \\
(0.68-1.30) \\
\end{array}$ & $\begin{array}{l}0.80 \\
(0.55-1.15) \\
\end{array}$ & $\begin{array}{l}-11.8 \\
(-36.4 ; 12.9) \\
\end{array}$ & & \\
\hline \multicolumn{9}{|l|}{ Major bleeding } \\
\hline Untreated & 10 & 1403.5 & $\begin{array}{l}7.1 \\
(3.4-13.1)\end{array}$ & 1 & 1 & & 1 & \\
\hline $\begin{array}{l}\text { First OAC treatment } \\
\text { episode }^{\mathrm{a}}\end{array}$ & 11 & 1121.2 & $\begin{array}{l}9.8 \\
(4.9-17.6)\end{array}$ & $\begin{array}{l}1.39 \\
(0.59-3.29)\end{array}$ & $\begin{array}{l}1.48 \\
(0.59-3.72)\end{array}$ & $\begin{array}{l}3.4 \\
(-10.4 ; 17.1)\end{array}$ & $\begin{array}{l}1.40 \\
(0.53-3.70)\end{array}$ & $\begin{array}{l}2.7 \\
(-9.7 ; 15.0)\end{array}$ \\
\hline $\begin{array}{l}\text { First AP treatment } \\
\text { episode }^{\mathrm{a}}\end{array}$ & 16 & 1300.4 & $\begin{array}{l}12.3 \\
(7.0-20.0)\end{array}$ & $\begin{array}{l}1.72 \\
(0.78-3.79)\end{array}$ & $\begin{array}{l}1.51 \\
(0.63-3.61)\end{array}$ & $\begin{array}{l}3.9 \\
(-10.4 ; 18.2)\end{array}$ & $\begin{array}{l}1.47 \\
(0.60-3.59)\end{array}$ & $\begin{array}{l}3.6 \\
(-9.7 ; 16.9)\end{array}$ \\
\hline
\end{tabular}

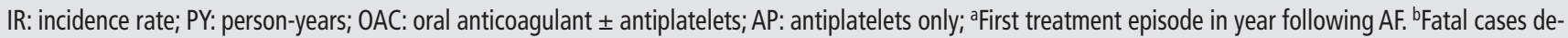
fined as outcome events recorded as primary, secondary or tertiary cause of death in death certificates. CHR derived using proportional hazards models for allcause mortality and subhazard ratios for stroke, MI and major bleeding. Adjusted for age, gender, smoking, hypertension, diabetes, previous TIA/stroke, coronary artery disease, peripheral artery disease, previous bleeding, cancer, AP therapy in previous year and Charlson index $(0,1,2,4,5+)$. 'Sensitivity analysis excluding patients with prior history of stroke/TIA in outcome stroke; history of $\mathrm{MI}$ in outcome Ml; and prior major bleeding in outcome major bleeding.

symptomatic or hospitalised patients with AF. Although we do not have a population of IA-AF detected by screening, the patients described are likely representative of those who might be discovered by systematic or opportunistic screening for AF in general practice, or by community screening.

We found a strong association between absolute risk increment of all major endpoints and age, becoming steeper over age 65 . This would justify OAC prescription and also inform age cut-off for screening. It is the basis of addition of another point for age $\geq 65$ in $\mathrm{CHA}_{2} \mathrm{DS}_{2} \mathrm{VASc}$ compared to $\mathrm{CHADS}_{2}$, which improves definition of truly low risk.(28) While risk of both stroke and death increased from age 50, there was a steeper increase above 65 , which coupled with lower incidence rate of IA-AF below 65 (22), would justify the new ESC recommendation for opportunistic screening for AF at age $\geq 65$ (2).

The adverse event rate we observed is similar in magnitude to that seen in recent randomised trials of $\mathrm{AF}$, where $\mathrm{CHADS}_{2}$ scores were usually higher, though all were on warfarin or non-VKA oral anticoagulants in RE-LY (29), ROCKET (30), and ARISTOTLE (31). Crude all cause cumulative mortality was approximately $12 \%$ after three years in the AFFIRM study (most on OAC), with stroke rate approximately $1 \%$ per annum (32). Annual incidence of stroke or systemic embolism on warfarin was 16.9/1,000 person years in RE-LY, 24 in ROCKET, and 16.0 in ARISTOTLE, while 


\section{What is known about this topic?}

- Atrial fibrillation (AF) is associated with a significant increase in risk of stroke and death.

- Disabling stroke is often the first manifestation of $A F$, so opportunistic screening of those $\geq 65$ years is advocated in some guidelines to reduce stroke from previously unknown AF.

- Although AF-related strokes are largely preventable by oral anticoagulants (OAC), prognosis of asymptomatic AF discovered by opportunistic or systematic screening is unknown as is its response to anti-thrombotic therapy.

\section{What does this paper add?}

- To the best of our knowledge, this is the first study of incidentally detected ambulatory AF and follows a very large cohort for three years.

- There is a high risk of stroke and death compared to controls without $A F$, and treatment with OAC (but not aspirin) is associated with a significant reduction of both stroke and death.

- The risks and benefits of treatment are similar to that seen in other studies of AF in symptomatic and hospitalised patients, and should be applicable to subjects or patients detected by community or clinic screening for AF.

all-cause mortality was 41.3/1,000 person-years in RE-LY, 40 in ROCKET, and 39.4 in ARISTOTLE. Notably, the stroke rate is similar to that seen in the recent Canadian population study of incident AF in those $>65$ (18.4/1,000 person-years) (33).

No trials have prospectively randomised patients with IA-AF to anticoagulant or antiplatelet therapy, although a small number of the BAFTA study (34) detected by screening were randomised to either OAC (146 patients) or aspirin (143 patients). The study by Flaker et al. (17) did identify 481 with asymptomatic AF from the AFFIRM study, but it was not known if they were detected incidentally, and over $90 \%$ were on OAC, making it difficult to draw conclusions on prognosis of IA-AF from that study. The Belgrade study (35) did follow a small group of 110 patients with asymptomatic AF, but there was no information on whether these were detected incidentally, and the mean age was 53 , indicating likely significant referral bias to the clinic from which the data were drawn. Similarly in the RACE study (36), the prognosis of 157 patients who were currently asymptomatic was studied, but there was no information on whether these patients had been originally symptomatic, nor whether AF had been detected incidentally. In no study has the prognosis of IA-AF been compared with a contemporaneous matched cohort without AF.

In this study we found that OAC treatment was associated with a significant reduction in stroke (adjusted HR 0.35), similar in magnitude to that seen in meta-analysis of the OAC studies (15). This occurred with a relatively small increase in major bleeding incidence of 3.4/1,000 person years. It is likely that the net clinical benefit may be greater for the non-VKA oral anticoagulants which were not available during the study period (37). Of course the ad- verse effects of OACs are dependent on the quality of INR control as reflected by the time in therapeutic range (31) which was not measured in this study. The reduction in total mortality seen with OACs in our study (adjusted HR=0.56; 0.36-0.85) was somewhat greater than that seen in early OAC studies $(26 \%$ relative risk reduction (3-43\%) (15), while antiplatelet therapy, largely with aspirin, showed no statistically significant reduction of either stroke or mortality, but showed a non-significant increase in major bleeding similar to OACs. Failure to find a significant small protective effect of antiplatelets on stroke or mortality could be a type 2 error, but is in keeping with latest analyses of data from large registries which found aspirin was not protective for thromboembolism but still had an appreciable risk of stroke $(38,39)$, indicating that aspirin has little place in thromboprophylaxis in $\mathrm{AF}$ and is being progressively removed from guidelines (2).

The major potential limitation of observational studies is selection bias of diagnosis of IA-AF and residual confounding, e.g. if OAC use in practices finding IA-AF were not representative or if untreated IA-AF had a different risk than those in our cohort who remain untreated. As our data were drawn from all GP practices contributing to the CPRD, selection bias based on practice is unlikely. Adjusted cumulative risk estimates for comparisons of IA$\mathrm{AF}$ and non-AF cohort outcomes did not change appreciably after adjustment for individual $\mathrm{CHA}_{2} \mathrm{DS}_{2}$ VASc components, smoking, previous bleeding, cancer, antiplatelet therapy in previous year and Charlson index, and a sensitivity analysis excluding patients with a prior endpoint did not appreciably change the result, making residual confounding unlikely to explain the study treatment findings, but it is impossible to exclude an influence of residual confounding on our results. A placebo-controlled trial would be required to be certain that $\mathrm{OAC}$ treatment is justified in IA-AF, though such a trial is unlikely to be carried out due to lack of equipoise.

While we carefully excluded any patient with symptoms by examining 'Read Medical Codes' from all practitioner records of the index consultation, and excluded those with heart failure in whom symptoms could be confused, as well as all hospital-diagnosed AF, it is possible that some patients had a non-specific symptom not elicited by the general practitioner, or that the patient had a symptom that was not recorded in the 'Read Medical Codes'. However, we feel symptoms were unlikely to have been missed in the first practitioner recording of AF diagnosis. Similarly, in those patients excluded because of symptoms recorded in the 'Read Medical Codes', we have no way of checking whether the patient actually had experienced that symptom. Additionally, it is not possible to ascertain the precise reason for the consultation during which AF was diagnosed incidentally, as the 'Read Medical Codes were dominated by the finding of new AF.

The rationale for screening depends on the rate of AF detection in various age groups and the event rate in detected subjects. In our systematic review we showed a $1.4 \%$ incidence of previously undetected AF with a single screening episode in those $\geq 65$, and no difference in incidence between clinic and community settings (22). While systematic screening with 12-lead ECG was not found cost-effective (40), less expensive automated screening can be ac- 
complished more quickly and easily with a handheld ECG which has high accuracy to diagnose AF (41) and can easily be applied in the community (42), changing cost-effectiveness estimates. Our recently reported SEARCH-AF study demonstrated that a single handheld ECG screen in pharmacies was likely to be cost-effective in prevention of stroke and stroke-related disability (42).

In summary, incidental ambulatory AF is common and is associated with a serious risk of stroke, death, and MI compared to age- and gender-matched controls. OAC treatment was associated with reduction of stroke and death, while antiplatelet therapy, largely with aspirin, was not. The high event rate, coupled with the known $1.4 \%$ detection rate (22) and likely effectiveness of OAC in preventing stroke and reducing death, argue strongly not only for opportunistic AF screening as recommended in guidelines, but probably for more comprehensive targeted population screening for age $\geq 65$ to reduce the burden of stroke and premature death associated with this often asymptomatic and undetected arrhythmia.

\section{Conflicts of interest}

$\mathrm{CM}$ reports grants, personal fees and non-financial support from Bayer Pharma AG, personal fees from Boehringer Ingelheim, grants and personal fees from CSL Behring, outside the submitted work. AK has nothing to disclose. SBF reports grants, personal fees and non-financial support from Bayer Pharma AG outside the submitted work, grants and non-financial support from Boehringer Ingelheim outside the submitted work, grants and personal fees from BMS/Pfizer outside the submitted work, personal fees from Servier outside the submitted work, personal fees from AstraZeneca, outside the submitted work.

\section{References}

1. Miyasaka Y, Barnes ME, Gersh BJ, et al. Secular trends in incidence of atrial fibrillation in Olmsted County, Minnesota, 1980 to 2000, and implications on the projections for future prevalence. Circulation 2006; 114: 119-125.

2. Camm AJ, Lip GYH, Caterina RD, et al. 2012 focused update of the ESC Guidelines for the management of atrial fibrillation. An update of the 2010 ESC Guidelines for the management of atrial fibrillation. Developed with the special contribution of the European Heart Rhythm Association. Eur Heart J 2012; 33: 2719-2747.

3. Lin HJ, Wolf PA, Kelly-Hayes M, et al. Stroke severity in atrial fibrillation. The Framingham Study. Stroke 1996; 27: 1760-1764.

4. Kimura K, Minematsu K, Yamaguchi T. Atrial fibrillation as a predictive factor for severe stroke and early death in 15,831 patients with acute ischaemic stroke. J Neurol Neurosurg Psychiatry 2005; 76: 679-683.

5. Benjamin EJMDS, Wolf PAMD, D'Agostino RBP, et al. Impact of Atrial Fibrillation on the Risk of Death: The Framingham Heart Study. Circulation 1998; 98: 946-952.

6. Wang TJ, Larson MG, Levy D, et al. Temporal relations of atrial fibrillation and congestive heart failure and their joint influence on mortality: the Framingham Heart Study. Circulation 2003; 107: 2920-2925.

7. Hannon N, Sheehan O, Kelly L, et al. Stroke associated with atrial fibrillation incidence and early outcomes in the North Dublin population stroke study. Cerebrovasc Dis 2010; 29: 43-49.

8. Leyden JM, Kleinig TJ, Newbury J, et al. Adelaide stroke incidence study: declining stroke rates but many preventable cardioembolic strokes. Stroke 2013; 44: 1226-1231.

9. Bhatt A, Majid A, Razak A, et al. Predictors of Occult Paroxysmal Atrial Fibrillation in Cryptogenic Strokes Detected by Long-Term Noninvasive Cardiac
Monitoring. Stroke Res Treatm 2011; 2100: Article ID 172074, doi 10.4061/2011/172074.

10. Stahrenberg RMD, Weber-Kruger M, Seegers JMD, et al. Enhanced Detection of Paroxysmal Atrial Fibrillation by Early and Prolonged Continuous Holter Monitoring in Patients With Cerebral Ischemia Presenting in Sinus Rhythm. Stroke 2010; 41: 2884-2888.

11. Healey JS, Connolly SJ, Gold MR, et al. Subclinical Atrial Fibrillation and the Risk of Stroke. N Engl J Med 2012; 366: 120-129.

12. Hannon N, Sheehan O, Kelly L, et al. Stroke associated with atrial fibrillation-incidence and early outcomes in the north Dublin population stroke study. Cerebrovasc Dis 2010; 29: 43-49.

13. Deif B, Lowres N, Freedman SB. Screening for atrial fibrillation above age 65 detects an asymptomatic subset at high risk of stroke. Int J Cardiol 2013;164: 371-372.

14. Medi C, Hankey GJ, Freedman SB. Stroke risk and antithrombotic strategies in atrial fibrillation. Stroke 2010; 41: 2705-2713.

15. Hart RG, Pearce LA, Aguilar MI. Meta-analysis: antithrombotic therapy to prevent stroke in patients who have nonvalvular atrial fibrillation. Ann Intern Med 2007; 146: 857-867.

16. Glotzer TV, Daoud EG, Wyse DG, et al. The relationship between daily atrial tachyarrhythmia burden from implantable device diagnostics and stroke risk: the TRENDS study. Circ Arrhythm Electrophysiol 2009; 2: 474-480.

17. Flaker GC, Belew K, Beckman K, et al. Asymptomatic atrial fibrillation: demographic features and prognostic information from the Atrial Fibrillation Followup Investigation of Rhythm Management (AFFIRM) study. Am Heart J 2005; 149: 657-663.

18. Stott DJ, Dewar RI, Garratt CJ, et al. RCPE UK Consensus Conference on 'approaching the comprehensive management of atrial fibrillation: evolution or revolution?'. J R Coll Physicians Edinb 2012; 42: 34-35.

19. Fuster V, Ryden LE, Cannom DS, et al. 2011 ACCF/AHA/HRS focused updates incorporated into the ACC/AHA/ESC 2006 Guidelines for the management of patients with atrial fibrillation: a report of the American College of Cardiology Foundation/American Heart Association Task Force on Practice Guidelines developed in partnership with the European Society of Cardiology and in collaboration with the European Heart Rhythm Association and the Heart Rhythm Society. J Am Coll Cardiol 2011; 57: e101-198.

20. Fuster V, Ryden LE, Cannom DS, et al. ACC/AHA/ESC 2006 Guidelines for the Management of Patients with Atrial Fibrillation: a report of the American College of Cardiology/American Heart Association Task Force on Practice Guidelines and the European Society of Cardiology Committee for Practice Guidelines (Writing Committee to Revise the 2001 Guidelines for the Management of Patients With Atrial Fibrillation): developed in collaboration with the European Heart Rhythm Association and the Heart Rhythm Society. Circulation 2006; 114: e257-354.

21. January CT, Wann LS, Alpert JS, et al. 2014 AHA/ACC/HRS Guideline for the Management of Patients With Atrial Fibrillation: A Report of the American College of Cardiology/American Heart Association Task Force on Practice Guidelines and the Heart Rhythm Society. J Am Coll Cardiol 2014; Epub ahead of print.

22. Lowres N, Neubeck L, Redfern J, et al. Screening to identify unknown atrial fibrillation. A systematic review. Thromb Haemost 2013; 110: 213-222.

23. Schulman S, Kearon C. Definition of major bleeding in clinical investigations of antihemostatic medicinal products in non-surgical patients. J Thromb Haemost 2005; 3: 692-694.

24. Satagopan JM, Ben-Porat L, Berwick M, et al. A note on competing risks in survival data analysis. Br J Cancer 2004; 91: 1229-1235.

25. Fine J, Gray R. A proportional hazards model for the subdistribution of a competing risk. J Am Stat Assoc 1999; 94: 496-509.

26. Hastie T, Tibshirami R. Generalized additive models for medical research. Stat Methods Med Res 1995; 4: 187-196.

27. Wood SN. Modelling and smoothing parameter estimation with multiple quadratic penalties. J Royal Stat Soc 2000; 62: 413-428.

28. Olesen JB, Torp-Pedersen C, Hansen ML, et al. The value of the CHA2DS2-VASc score for refining stroke risk stratification in patients with atrial fibrillation with a CHADS2 score 0-1: a nationwide cohort study. Thromb Haemost 2012; 107: 1172-1179.

29. Connolly SJ, Ezekowitz MD, Yusuf S, et al. Dabigatran versus warfarin in patients with atrial fibrillation. N Engl J Med 2009; 361: 1139-1151. 
30. Patel MR, Mahaffey KW, Garg J, et al. Rivaroxaban versus warfarin in nonvalvular atrial fibrillation. N Engl J Med 2011; 365: 883-891.

31. Granger CB, Alexander JH, McMurray JJ, et al. Apixaban versus warfarin in patients with atrial fibrillation. N Engl J Med 2011; 365: 981-992.

32. Wyse DG, Waldo AL, DiMarco JP, et al. A comparison of rate control and rhythm control in patients with atrial fibrillation. N Engl J Med 2002; 347: 1825-1833.

33. Tsadok MA, Jackevicius CA, Rahme E, et al. Sex Differences in Stroke Risk Among Older Patients With Recently Diagnosed Atrial Fibrillation. J Am Med Assoc 2012; 307: 1952-1958.

34. Mant J, Hobbs FD, Fletcher K, et al. Warfarin versus aspirin for stroke prevention in an elderly community population with atrial fibrillation (the Birmingham Atrial Fibrillation Treatment of the Aged Study, BAFTA): a randomised controlled trial. Lancet 2007; 370: 493-503.

35. Potpara TS, Polovina MM, Marinkovic JM, et al. A comparison of clinical characteristics and long-term prognosis in asymptomatic and symptomatic patients with first-diagnosed atrial fibrillation: the Belgrade Atrial Fibrillation Study. Int J Cardiol 2013; 168: 4744-4749.

36. Rienstra M, Vermond RA, Crijns HJ, et al. for the RI. Asymptomatic persistent atrial fibrillation and outcome: Results of the RACE study. Heart Rhythm 2014; Epub ahead of print.
37. Banerjee A, Lane DA, Torp-Pedersen C, et al. Net clinical benefit of new oral anticoagulants (dabigatran, rivaroxaban, apixaban) versus no treatment in a 'real world' atrial fibrillation population: a modelling analysis based on a nationwide cohort study. Thromb Haemost 2012; 107: 584-589.

38. Olesen JB, Lip GY, Lindhardsen J, et al. Risks of thromboembolism and bleeding with thromboprophylaxis in patients with atrial fibrillation: A net clinical benefit analysis using a 'real world' nationwide cohort study. Thromb Haemost 2011; 106: 739-749.

39. Sjalander S, Sjalander A, Svensson PJ, et al. Atrial fibrillation patients do not benefit from acetylsalicylic acid. Europace 2014; 16: 631-638.

40. Hobbs FDR, Fitzmaurice DA, Mant J, et al. A randomised controlled trial and cost-effectiveness study of systematic screening (targeted and total population screening) versus routine practice for the detection of atrial fibrillation in people aged 65 and over. The SAFE study. Health Technol Assess 2005; 9: iii-iv, ix-x, $1-74$.

41. Lau JK, Lowres N, Neubeck L, et al. iPhone ECG application for community screening to detect silent atrial fibrillation: a novel technology to prevent stroke. Int J Cardiol 2013; 165: 193-194.

42. Lowres N, Freedman SB, Redfern J, et al. Screening Education And Recognition in Community pHarmacies of Atrial Fibrillation to prevent stroke in an ambulant population aged $>=65$ years (SEARCH-AF stroke prevention study): a cross-sectional study protocol. Br Med J Open 2012; 2: e0011355.

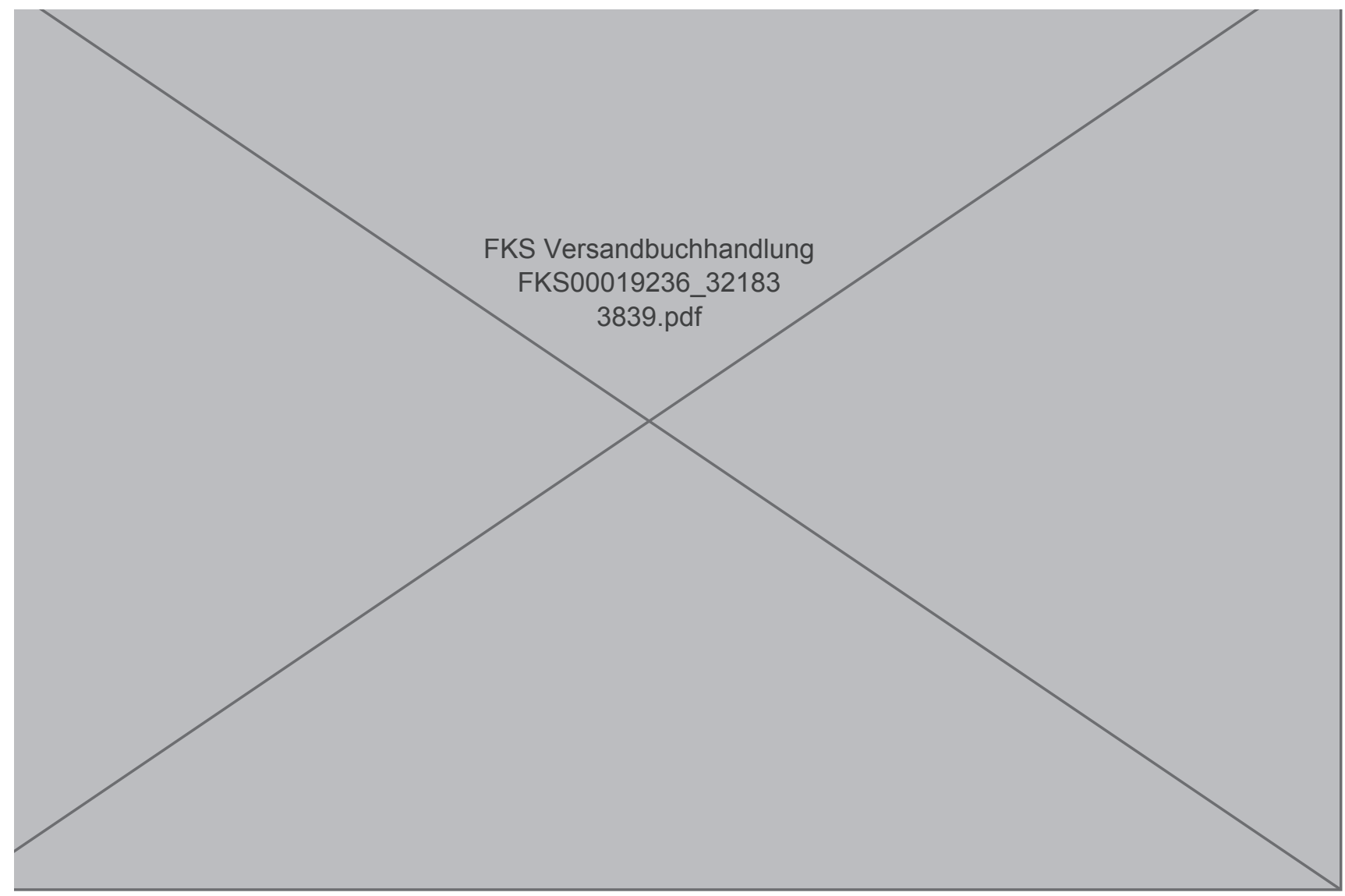

